\title{
Severe upper airway obstruction caused by ulcerative laryngitis
}

\author{
M Hatherill, L Reynolds, Z Waggie, A Argent
}

\begin{abstract}
Aims-To present our experience of severe upper airway obstruction caused by ulcerative laryngitis in children.

Methods-Retrospective case note review of 263 children with severe upper airway obstruction and a clinical diagnosis of croup admitted to a paediatric intensive care unit (PICU) over a five year period. Results-A total of 148 children (56\%) underwent microlaryngoscopy (Storz 3.0 rigid telescope). Laryngeal ulceration with oedema was documented in 15 of these children (10\%), median age 14 months (range 10-36) and median weight $10 \mathrm{~kg}$ (range 6-12). Twenty seven of the children who underwent microlaryngoscopy $(\mathbf{1 8 \%})$ also had ulcerative gingivostomatitis consistent with herpes simplex virus infection. Ulcerative laryngitis was documented in nine of $27(33 \%)$ children with, and in six of $121(5 \%)$ children without, coexistent ulcerative gingivostomatitis. One of the 15 children did not require airway intervention. Nine children required nasotracheal intubation for a median of 4 days (range 3-11) and median PICU stay of 6 days (range 4-14). Five children required tracheostomy ab initio, with a median PICU stay of 30 days (range 20-36), and duration of tracheostomy in situ for a median of 19 days (range 15-253). All 15 children survived.

Conclusion-Ulcerative laryngitis is more common in our patient population than the few reports suggest. Early diagnostic microlaryngoscopy is recommended in children with severe croup who follow an atypical course.

(Arch Dis Child 2001;85:326-329)
\end{abstract}

Keywords: ulcerative laryngitis; croup; herpes simplex; microlaryngoscopy

Paediatric Intensive Care Unit, Institute of Child Health, Red Cross War Memorial Children's Hospital, Klipfontein Road, Cape Town, 7700, South Africa

M Hatherill

L Reynolds

Z Waggie

A Argent

Correspondence to: Dr Hatherill

hatheril@ich.uct.ac.za

Accepted 11 June 2001
Ulcerative laryngitis or laryngotracheitis is rarely documented in children. ${ }^{12}$ The importance of recognising this condition lies in the need for early diagnosis and treatment of herpetic laryngeal disease. ${ }^{12}$ Herpes simplex virus has been recognised not only as a cause of ulcerative laryngitis, but also of epiglottic, tracheal, and bronchial disease in immunocompetent children. ${ }^{1-5}$ However, a low index of suspicion in previously well children may delay both diagnosis and antiviral treatment, unless early formal laryngoscopy is performed. ${ }^{346}$ The possibility of ulcerative laryngitis in children with a clinical diagnosis of nonspecific viral croup also has implications for the routine use of inhaled or oral steroids in the emergency department setting. ${ }^{78}$

It has been our impression that the incidence of ulcerative laryngitis found at microlaryngoscopy in our patients is higher than the few existing case reports would suggest. ${ }^{12}$ We present our experience of severe upper airway obstruction caused by ulcerative laryngitis in children over a five year period.

\section{Methods}

We performed a retrospective case note review in an 11 bed paediatric intensive care unit (PICU) of a university children's hospital serving the Western Cape province of South Africa. The medical records of all 263 children with severe upper airway obstruction and a clinical diagnosis of croup, who required admission to the PICU over the period January 1994 to December 1998, were reviewed. Further data were collected on the 148 children (56\%) who underwent diagnostic microlaryngoscopy and who form the basis of this report.

\section{CLINICAL MANAGEMENT}

During this period, children at this institution presenting with presumed viral croup were treated with a regimen of oral steroids combined with adrenaline nebulisations. The severity of airway obstruction caused by croup was assessed using the scoring system of Klein, and patients were referred for intensive care if grade 3 obstruction was present (inspiratory and expiratory stridor with pulsus paradoxus). ${ }^{9}$ According to routine practice, all 147 children $(56 \%)$ who subsequently required airway intervention (either endotracheal intubation or tracheostomy) on clinical grounds underwent a diagnostic microlaryngoscopy at that time. One child who did not require airway intervention, but who had a prolonged clinical course, also underwent microlaryngoscopy. Microlaryngoscopy was performed by one of four clinicians using a Storz 3.0 rigid telescope, under inhalational anaesthesia via nasopharyngeal insufflation. The appearance of the airway was noted, and ulcerative laryngitis was diagnosed in the presence of characteristic laryngeal ulceration and oedema, with or without erythema and exudation (see fig 1 ).

During the period studied, it was not routine practice for children with ulcerative laryngitis to be tested for human immunodeficiency virus (HIV) in the absence of other clinical features to support the diagnosis. Nor was it standard practice for viral immunofluorescence or culture to be requested for all children with ulcerative laryngitis in whom herpes simplex was suspected. Steroid therapy was stopped, 


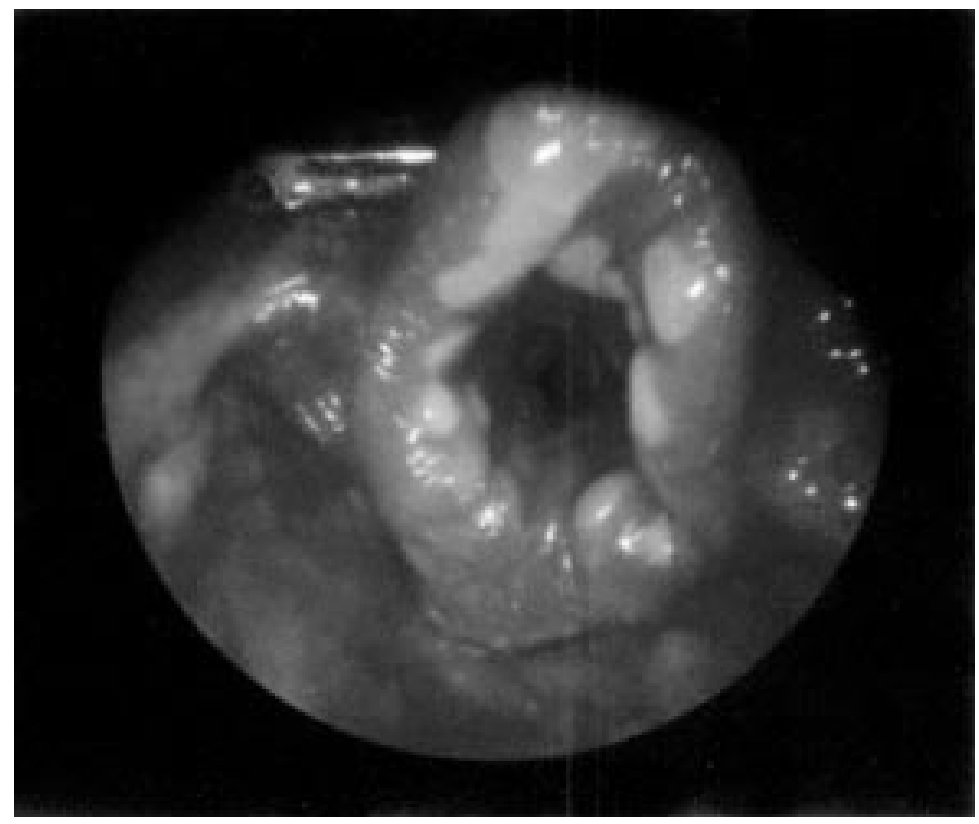

Figure 1 Characteristic appearance of ulcerative laryngitis; microlaryngoscopy shows extensive laryngeal oedema, erythema, and exudative plaques on an ulcerated base.

and intravenous acyclovir started empirically, in all children with croup who had evidence of either ulcerative gingivostomatitis, laryngitis, or both.

Suitability for endotracheal intubation was assessed on the basis of the microlaryngoscopy findings. In the presence of severe subglottic ulceration, a tracheostomy was performed in order to prevent further mucosal damage secondary to mechanical trauma. If ulceration was not severe, non-instrumental nasotracheal intubation (without using a Magill forceps) was attempted with a Portex ivory tube. If subglottic narrowing was such that a size 3.0 diameter tube could not be passed with ease, a tracheostomy was performed.

Intubated children underwent repeat microlaryngoscopy after three days of antiviral treatment, again under inhalational anaesthetic, in order to assess the degree of mucosal healing. If the oedema and ulceration had improved a trial of extubation was attempted. If healing was not observed the endotracheal tube was left in situ and the microlaryngoscopy repeated three days later.

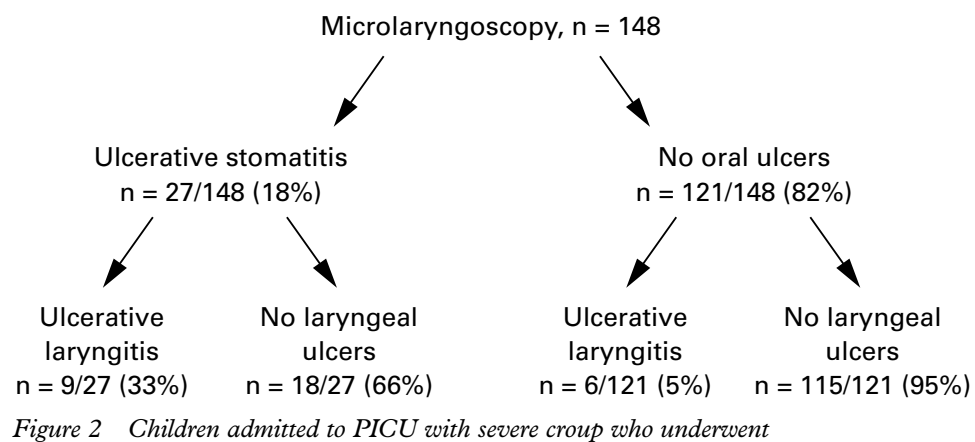

Figure 2 Children admitted to PICU with severe croup who underwent microlaryngoscopy: association between ulcerative gingivostomatitis and laryngitis.
RETROSPECTIVE DATA COLLECTION

The following data were recorded: macroscopic appearance of the oropharynx, microlaryngoscopic appearance of the larynx, viral culture and immunofluorescence (when available), dose and duration of acyclovir, number of children endotracheally intubated, size of endotracheal tube, duration of intubation (days), number of children requiring tracheostomy, duration that tracheostomy remained in situ (days), time to healing of lesions, duration of PICU stay (days), and mortality.

Data are reported as median (range) and analysed using the Mann-Whitney and Fisher's exact tests. All study data were collected retrospectively, and therefore institutional ethical approval was not required.

\section{Results}

MICROLARYNGOSCOPIC FINDINGS

A total of 147 children (56\%) underwent microlaryngoscopy at the time of airway intervention, and one child, who did not require airway intervention, underwent microlaryngoscopy on day 18 of the illness because of a relapsing course atypical of non-specific viral croup.

Ulcerative laryngitis with subglottic oedema was documented in 15 of these children, median age 14 months (range 10-36) and median weight $10 \mathrm{~kg}$ (range 6-12). The incidence of documented ulcerative laryngitis in children undergoing microlaryngoscopy was therefore $10 \%(n=15 / 148)$, and the overall incidence in children admitted to PICU with severe croup was $6 \% \quad(n=15 / 263)$. This incidence $(6 \%)$ was unchanged between the first 30 months of the study period (January 1994 to June 1996) ( $\mathrm{n}=9 / 154)$, compared to the second 30 months (June 1996 to December 1998) $(n=6 / 109)(p=0.56)$.

Twenty seven of the 263 children $(10 \%)$ had evidence of oropharyngeal ulceration characteristic of herpetic gingivostomatitis, and all of these children underwent microlaryngoscopy ( $\mathrm{n}=27 / 148 ; 18 \%)$. Ulcerative laryngitis was documented in nine of the 27 children (33\%) with, and in six of the 121 children (5\%) without, coexistent ulcerative gingivostomatitis $(p<0.002)$ (see fig 2$)$. The presence of oropharyngeal ulcers predicted the finding of ulcerative laryngitis at microlaryngoscopy with sensitivity and specificity of $80 \%$ and $86 \%$, and positive and negative predictive values of $33 \%$ and $95 \%$ respectively.

\section{INVESTIGATIONS}

Viral culture was available in six of the 15 children with ulcerative laryngitis, confirming herpes simplex virus $(\mathrm{n}=3)$ and cytomegalovirus $(n=1)$. Viral culture was negative in two children. Bacterial culture of tracheal aspirates taken at the time of microlaryngoscopy grew Haemophilus influenzae $(\mathrm{n}=5)$, Staphylococcus aureus $(\mathrm{n}=2)$, Streptococcus pneumoniae $(\mathrm{n}=1)$, Providentia rettgeri $(\mathrm{n}=1)$, and mixed commensals $(n=6)$. 
INTERVENTIONS

All children with either oropharyngeal or laryngeal ulceration received intravenous acyclovir 5-10 mg/kg per dose 8 hourly for a median of 5 days (range 2-7).

Nine children required nasotracheal intubation. Endotracheal tube sizes were $3.0 \mathrm{~mm}$ $(\mathrm{n}=7), 3.5 \mathrm{~mm}(\mathrm{n}=2)$, and $4.0 \mathrm{~mm}(\mathrm{n}=1)$. Four of the nine children (44\%) could not be extubated by day 3 because of persistent ulceration and swelling. Median time to healing of the mucosa sufficient to allow extubation was 4 days (range 3-11) and median PICU stay was 6 days (range 4-14).

Five children required insertion of a tracheostomy ab initio because of severe ulceration and swelling. These children required a longer PICU stay of median 30 days (range 20-36) $(p=0.002)$. However, we should note that all children with tracheostomies were cared for in a high dependency care area of the PICU, and therefore duration of PICU stay for these children equates to duration of hospital stay. Tracheostomies remained in situ for a median of 19 days (range 15-253).

One of the 15 children did not require airway intervention.

COMPLICATIONS AND OUTCOME

Aspiration caused by laryngeal incompetence was later shown by radiolabelled milk scan or methylene blue ingestion in five of the 15 children (33\%) with ulcerative laryngitis. All 15 children survived to hospital discharge.

\section{Discussion}

We have shown a higher incidence of ulcerative laryngitis in our patients with severe croup than the few published case reports would suggest $(10 \%$ of children undergoing microlaryngoscopy and $6 \%$ overall).$^{1-5}$ None of the children had received long term steroid therapy prior to diagnosis, nor was immunodeficiency suspected on clinical grounds. However, during the period of the study, it was not standard practice for patients with ulcerative laryngitis or gingivostomatitis consistent with herpes simplex disease to be investigated for human immunodeficiency virus (HIV), in the absence of clinical features to support that diagnosis.

It is possible that there is a higher incidence of primary oropharyngeal herpes simplex in our paediatric population (although no data exist) and that these results may not reflect the situation in developed countries. Our findings might also be influenced by case selection, as only children with severe obstruction were admitted to the PICU, and only those children who followed an atypical course (severity or duration) despite medical treatment underwent a microlaryngoscopy.

It might be argued that given the high incidence of ulcerative laryngitis in our patient population, the routine emergency department use of oral or inhaled steroids may be harmful to this subgroup of patients. ${ }^{78} \mathrm{Al}-$ though delay in diagnosis, with or without ongoing steroid treatment, and consequent delay in initiating antiviral therapy, may result in a prolonged clinical course, our data would not support the restriction of steroid therapy unless ulcerative laryngitis has been shown by microlaryngoscopy. ${ }^{346}$ While there has been a fall in PICU admissions for croup which has coincided with the widespread use of steroids over the second half of the study period, there has been no parallel increase in the overall incidence of ulcerative laryngitis ( $6 \%$ for both periods).

We have shown that the presence of ulcerative gingivostomatitis has poor predictive value for the finding of ulcerative laryngitis at microlaryngoscopy. If the presence of oropharyngeal ulcers alone were used to determine which children with croup should receive antiviral therapy, $66 \%$ of such children would be treated "unnecessarily", although it might be argued that many clinicians would continue antiviral therapy despite a negative microlaryngoscopy. It is of greater concern that $5 \%$ of children with croup without oropharyngeal ulcers (six children in our study) were shown to have ulcerative laryngitis. These children would not have received early antiviral therapy unless a microlaryngoscopy had been performed. Previous reports have also stressed the importance of a high index of suspicion for herpetic ulcerative laryngitis, with early endoscopy if symptoms persist. $^{1-36}$

The use of follow up microlaryngoscopy also allows evaluation of airway patency and mucosal healing as a guide to suitability for extubation. The relatively short period of intubation (median four days) reflects the experience of others once antiviral treatment has been initiated, with macroscopic healing within 10 days. $^{236}$ However, although few of these children had long term sequelae caused by tracheal stenosis, it is noteworthy that five children had evidence of subsequent laryngeal incompetence which was not suspected prior to the illness. These children are at risk of developing repeated chest infections secondary to aspiration. Identification of children with croup who have underlying ulcerative laryngitis may thus raise the index of suspicion for subsequent complications such as laryngeal incompetence.

The longer duration of PICU stay, and need for tracheostomy, in those children who are not suitable for intubation may reflect the severity of mucosal damage prior to acyclovir therapy. These children may require prolonged intensive care and in-hospital support despite prompt diagnosis. The fact that all children with ulcerative laryngitis survived to hospital discharge suggests that upper airway involvement is not necessarily associated with systemic or disseminated disease.

CONCLUSION

Ulcerative laryngitis is more common in our patient population than the few case reports suggest. The presence of oropharyngeal ulcers in children with croup should not be relied on to make the diagnosis. Early diagnostic microlaryngoscopy is recommended in children with severe croup who follow an atypical course. 
We acknowledge Professors $\mathrm{M}$ Klein and C Prescott for diagnostic microlaryngoscopy.

1 Harris JB, Lusk R, Wagener JS, Andersen RD. Acute viral laryngotracheitis complicated by herpes simplex infection. Otolaryngol Head Neck Surg 1987;96:190-3.

2 Mancao MY, Sindel LJ, Richardson PH, Silver FM. Herpetic croup: two case reports and a review of the literature. Acta Paediatr 1996;85:118-20.

3 Bogger-Goren S. Acute epiglottitis caused by herpes simplex virus. Pediatr Infect Dis ₹ 1987;6:1133-4.

4 Sofer S, Pagtakhan RD, Hoogstratten J. Fatal lower respiratory tract infection due to herpes simplex virus in a previously healthy child. Clin Pediatr 1984;23:406-9.
5 Benjamin DR. Herpes simplex tracheobronchitis and pneumonitis. Pediatr Pathol 1989;9:773-7.

6 Inglis I. Herpes simplex virus infection. A rare cause of prolonged croup. Arch Otolaryngol Head Neck Surg 1993;119: 551-2.

7 Johnson DW, Jacobson S, Edney PC, et al. A comparison of nebulized budesonide, intramuscular dexamethasone, and placebo for moderately severe croup. $N$ Engl $7 \mathrm{Med}$ 1998;339:498-503.

8 Jaffe DM. The treatment of croup with glucocorticoids. $N$ Engl f Med 1998;339:553-5.

9 Klein M. In: Oxford handbook of paediatrics, 4th edn. Cape Town: Oxford University Press, 1992:514.

\section{Archives of Disease in Childhood through the ages}

\section{Browse the Archive}

Archives of Disease in Childhood online has an archive of content dating back to 1973. Full text from 1997; abstracts from 1975; table of contents from 1973

www.archdischild.com 